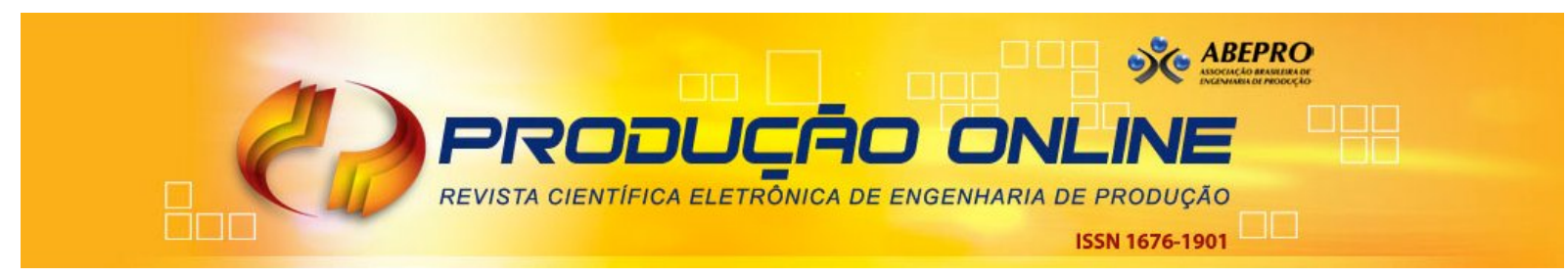

\title{
ANÁLISE DOS BENEFÍCIOS DE UM ESPAÇO LOGÍSTICO URBANO NA DISTRIBUIÇÃO URBANA DE MERCADORIAS
}

\section{ANALYSIS OF BENEFITIS OF URBAN LOGISTICS SPACE TO URBAN GOODS MOVEMENTS}

\author{
Leise Kelli de Oliveira* Email: leise@etg.ufma.br \\ Raissa Simonetti de Oliveira* Email: rarrasimo@yahoo.com.br \\ Rafaella de Souza Henriques** Email: rafaellahenriques@gmail.com \\ Martin Denais* Email: martin.denais@gmail.com \\ * Universidade Federal de Minas Gerais (UFMG), Belo Horizonte, MG \\ ** Centro Federal de Educação Tecnológica de Minas Gerais (CEFET-MG), Belo Horizonte, MG
}

Resumo: O transporte urbano de mercadorias é responsável por atender a cadeia de consumo das cidades, sendo essencial no desenvolvimento destas, apesar dos conflitos e problemas advindos da atividade. Nesse contexto, este trabalho apresenta uma análise da implantação de Espaços Logísticos Urbanos como centros de distribuição intermediários no transporte de mercadorias em áreas urbanas, utilizando veículos de cargas e triciclos elétricos para reduzir os impactos negativos da distribuição urbana de mercadorias. Para tanto, uma rede de transporte para a região central da cidade de Belo Horizonte foi desenvolvida e, utilizando-se das ferramentas de localização e roteamento do TransCAD®, obteve-se a localização do Espaço Logístico Urbano e as rotas de entrega entre o centro de distribuição, este espaço e o cliente final. Os resultados da análise indicam que os custos de operação, a quilometragem percorrida, número de veículos e emissão de poluentes são reduzidos com a implantação de um Espaço Logístico Urbano, com benefícios para a mobilidade urbana.

Palavras-Chaves: Distribuição Urbana de Mercadorias. Espaço Logístico Urbano. Mobilidade Urbana. Logística Urbana. TransCAD®.

\begin{abstract}
The urban freight transport is responsible for the city's consumption chain, being a key factor on urban development, despite all related conflicts and problems. In this context, this paper presents an analysis of the implementation of an Urban Logistic Space as an intermediate step in the urban goods distribution, using freight vehicle and electric tricycles. Therefore, a transport network for the central region of the city of Belo Horizonte was developed through Transcad $®$. An applicative for location and routing was utilized to locate the urban logistic space and get delivery routes among the distribution center, this space and the final customer. The results indicate that operational costs, distance traveled, the number of vehicles and emissions are reduced with the implementation of an Urban Logistic Space, providing benefits to urban mobility.
\end{abstract}

Keywords: Urban Goods Distribution. Urban Logistics Space. Urban Mobility. City Logistics. TransCAD®.

\section{INTRODUÇÃO}

O transporte urbano de mercadorias tem um papel fundamental no desenvolvimento das cidades, na medida em que estimula o comércio e impacta diretamente o estilo de vida da população (OLIVEIRA; OLIVEIRA, 2016). O aumento dos conges- 
tionamentos nos centros urbanos, da emissão de gases de efeito estufa e os transtornos causados no dia a dia dos habitantes que vivem e/ou convivem próximos às áreas de entrega são exemplos dos problemas gerados pela distribuição urbana. Dentro desse contexto, os transportadores necessitam prestar um serviço eficaz, de boa qualidade e com baixos custos.

Esse é uma situação desafiadora, já que, segundo Crainic et al. (2004), as autoridades promovem poucas políticas em relação ao transporte de mercadorias nas grandes cidades, atuando somente através de regulamentações restritivas à circulação e ao estacionamento de veículos. Tais fatos não são suficientes para promover uma melhora significativa nesse cenário.

Visando analisar e minimizar os problemas anteriormente citados, surgiu o conceito de Logística Urbana que, segundo Taniguchi et al. (2001), é um processo de otimização das atividades de logística em áreas urbanas considerando os impactos sociais, econômicos, financeiros e ambientais relacionados ao transporte urbano de mercadorias.

Dentre as alternativas relacionadas à Logística Urbana, destaca-se o Espaço Logístico Urbano (ELU). O ELU consiste em pontos de transbordo, na interface entre o envio e a recepção da mercadoria na área urbana, destinada a otimizar a entrega desses bens, considerando as questões operacionais e ambientais (BOUDOUIN, 2009; BOUDOUIN et al., 2014; APUR, 2016.).

A partir do ELU, as mercadorias são entregues com veículos de baixa emissão de poluentes, como veículos elétricos. Essa solução já é uma realidade em algumas cidades do mundo, especialmente francesas, podendo ser consideradas um exemplo de como os ELUs podem ser uma alternativa para o transporte urbano de mercadorias (TURBLOG, 2011).

Importante ressaltar que a literatura referente aos ELUs é limitada, apesar de ser indicada como uma solução para os problemas relacionados a distribuição urbana de mercadorias (DABLANC, 2011) e existir alguns exemplos implementados, principalmente, em cidades francesas. Assim, este trabalho destaca o espaço urbano de mercadorias como uma solução viável economicamente, e ambientalmente interessante para as entregas urbanas, demonstrando a importância da consolidação e utilização de veículos não motorizados nesta atividade. Para tanto, este artigo propõe um procedimento metodológico para avaliação da localização e dos benefícios de um ELU. Assim, utilizando as ferramentas de localização e roteamento de veículos do software TransCAD ${ }^{\circledR}$ (Transportation Planning Software), diferentes cenários foram analisados para identificar os benefícios com a implementação de um ELU, considerando o número de viagens, de veículos utilizados e os níveis de emissões de poluentes.

Para apresentar os resultados deste estudo, após esta seção introdutória, este artigo está assim dividido: a seção 2 aborda a revisão bibliográfica, identificando a importância da temática e evidenciando a contribuição técnica-científica do estudo. $\mathrm{Na}$ seção 3 é apresentado o procedimento metodológico, cujos resultados de um 
estudo de aplicação são apresentados na seção 4, finalizando o artigo com as considerações finais.

\section{DISTRIBUIÇÃO URBANA DE MERCADORIAS E OS ESPAÇOS LOGÍSTICOS URBANOS}

De acordo com a OECD (Organisation for Economic Cooperation and Development, 2003), a distribuição urbana de mercadorias consiste na entrega de bens de consumo em cidades e áreas suburbanas, incluindo o fluxo reverso de bens usados. Esse processo é, portanto, muito importante para as pessoas, na medida em que garante o abastecimento do varejo e possibilita a entrega de mercadorias tanto em domicílios quanto em empresas localizadas nos centros urbanos, pois forma uma cadeia vital entre fornecedores e consumidores.

Além disso, Prata et al. (2012) destacam que a movimentação urbana de mercadorias inclui o transporte de bens acabados, o transporte de matérias-primas, a distribuição de mercadorias nos centros urbanos, os serviços de entrega rápida e as entregas domiciliares. Fica evidente, assim, a importância dessa atividade para o sistema de transporte urbano, visto que impacta na eficiência da cadeia logística e na qualidade do serviço dos transportadores.

Apesar da importância da distribuição urbana de mercadorias para a vitalidade econômica de uma cidade (OLIVEIRA; CORREIA, 2014), esta atividade provoca consequências negativas para as áreas urbanas. Segundo Crainic et al. (2004), os veículos que realizam as entregas competem por espaço nas vias com os veículos de passeio, contribuindo significativamente para o aumento dos congestionamentos e da poluição atmosférica e sonora.

$\mathrm{Na}$ maioria dos centros urbanos, os problemas relacionados com o transporte de carga urbana têm piorado nos últimos anos e, dentre as causas dessa piora, destacam-se a falta de políticas promovidas pelas autoridades públicas, o aumento da frota de veículos e as mudanças do processo de distribuição urbana. Dentre essas mudanças, Heitz (2015) confirma a previsão de Crainic et al. (2004), que ressaltam que o crescimento do comércio eletrônico e da logística expressa tem gerando significativo volume de entregas domiciliares em curtos períodos de tempo.

Em busca de soluções para os problemas gerados pela distribuição urbana de mercadorias, o conceito denominado Logística Urbana, e proposto por Taniguchi et al. (2001), incorpora a otimização das atividades de logísticas, realizadas por entidades públicas ou privadas em áreas urbanas, considerando fatores como tráfego, congestionamento e consumo de energia na estrutura do mercado econômico. Esse conceito baseia-se na compreensão dos problemas que incluem custos de distribuição, sociais e ambientais.

Assim, para obter um sistema de distribuição de mercadorias dentro dos princípios da Logística Urbana, é necessário o envolvimento de quatro agentes: os embarcadores, os transportadores, a população e o poder público (TANIGUCHI et al., 
2001; OLIVEIRA; OLIVEIRA, 2016). Segundo os autores mencionados, cada um destes agentes tem seus próprios objetivos, mas todos eles devem se relacionar, seja de forma direta ou indireta.

Os embarcadores são os clientes dos transportadores. Eles recebem e enviam produtos para outras empresas e tendem a maximizar o nível de serviço, minimizando o custo e o tempo de coleta/entrega. Os transportadores realizam a distribuição de mercadorias objetivando minimizar os custos das coletas/entregas de produtos, aumentando assim o lucro. Tal tarefa é cada vez mais difícil nos dias atuais com os congestionamentos e as restrições de horários de circulação de veículos.

A população, por sua vez, é composta pelas pessoas que vivem, trabalham e consomem nos centros urbanos. Ela é afetada diretamente pelo fluxo de veículos e mercadorias. Já o poder público se apresenta como o intermediador entre os três agentes descritos anteriormente. É seu dever promover o desenvolvimento econômico da cidade com a geração de emprego e renda, mas também prezar pela qualidade de vida da população. Logo, ele também deve promover políticas visando à redução dos congestionamentos, do ruído, da emissão de poluentes e dos acidentes de trânsito. Para tanto, ele deve recorrer às soluções de Logística Urbana.

Dentre as soluções para propostas para os problemas de distribuição urbana de mercadorias (soluções de Logística Urbana) estão a implantação de infraestrutura que inclui áreas de carga e descarga; a melhoria na qualidade de vias; a criação de Espaços Logísticos Urbanos; o desenvolvimento de um sistema para otimizar o descarregamento dos veículos; a criação de um sistema inteligente de transporte que permita a comunicação entre transportadoras e motoristas no momento de definição da rota e do tempo previsto para descarregamento; e o estabelecimento de políticas públicas que incluem medidas restritivas de circulação de veículos de carga em uma janela de tempo ou ainda medidas permitindo a sua circulação em pistas de ônibus. Além disso, e extremamente importante, é o investimento em veículos de baixa emissão de poluentes para promoção de uma cidade com melhor qualidade de vida (DABLANC et al., 2013).

Como as soluções propostas pela Logística Urbana consideram o contexto analisado e os objetivos a serem alcançados, elas podem ser classificadas quanto aos seus locais e níveis de abrangência. Sendo assim, Frelon (2011) apresenta as soluções propostas pela Logística Urbana por meio de três níveis estratégicos, conforme apresentado na Figura 1. 
Figura 1 - Níveis estratégicos para a Logística Urbana

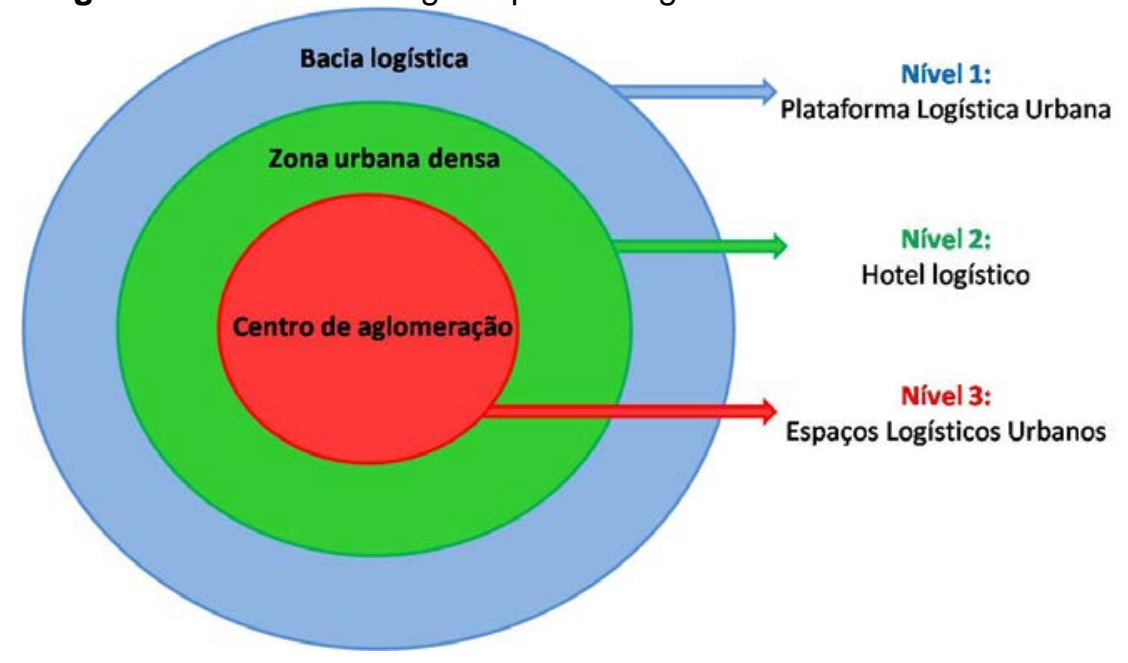

Fonte: Adaptado de Frelon (2011)

Considerando a Figura 1, a Plataforma Logística é um lugar com acessibilidade multimodal para armazenamento dos produtos. Um dos objetivos é disponibilizar os produtos próximo das principais vias urbanas, dos centros urbanos e, por consequência, dos clientes. Assim, as plataformas encontram-se próximas de rodovias e aeroportos e servem para minimizar os custos de transporte, estimular a produtividade, aumentar o número de encomendas e atendendo aos requisitos dos clientes, especialmente no que diz respeito à entrega (FRELON, 2011).

Já o Hotel Logístico consiste em um edifício de vários andares, cujo térreo e o primeiro nível são alocados para as atividades de Logística Urbana (varejo, correio, frete expresso, estoques), enquanto os níveis superiores se dedicam a outras atividades relacionadas ao transporte. Essa diversidade de atividades é uma forma de retorno do investimento realizado na implantação de toda a estrutura, podendo proporcionar, de forma sustentável, a reintrodução da logística em zonas urbanas densas (FRELON, 2011; BOUDOIN et al., 2014).

Por fim, o ELU tem por objetivo otimizar a entrega de mercadorias, considerando questões operacionais e ambientais, para a implantação de pontos de transbordo em centros urbanos (BOUDOIN et al., 2014; APUR, 2016). O ELU pode ser utilizado por diversas empresas, buscando consolidar entregas para uma maior utilização da capacidade dos veículos de transporte da "última milha". O transporte da última milha, tradução do termo inglês last mile, é utilizado em planejamento de transporte para descrever o movimento de mercadorias entre os principais terminais de transporte e o destino final. Por sua vez, o problema da última milha implica em encontrar soluções para resolver o problema de percorrer as últimas distâncias com baixos custos, pois é nesta fase final das operações que os custos logísticos crescem exponencialmente (VAN DUIN et al., 2016). O ELU minimiza a distância percorrida pelos veículos de carga nos centros urbanos, reduzindo também o congestionamento (VAN DUIN et al., 2016). 
Segundo SUGAR Logistics (2011), durante a década de 1990, os Centros de Distribuição Urbana (CDUs) foram considerados a solução com melhor potencial para diminuir o fluxo de veículos comerciais em áreas urbanas densas, mas vários desses projetos foram abandonados em função de seus custos ou de sua insuficiente utilidade. Oliveira e Correia (2014) apresentam uma revisão do conceito de CDU e indicam que este é uma instalação logística situada relativamente próxima à área urbana, em que as entregas são consolidadas e realizadas dentro desta área. Além disso, Oliveira e Correia (2014) indicam que os ELUs podem ser considerados pontos de apoio para a distribuição a partir de um CDU.

Dentre as estratégias existentes, em 1993, o ministério dos Transportes e a Agência de Meio-ambiente da França implementou o programa "Mercadorias Urbanas", que visava buscar soluções alternativas para a distribuição urbana de produtos (DABLANC, 2007). Destaca-se que Paris possui uma política de transporte urbano de mercadorias que incentiva ações experimentais para prover novas formas de entrega de produtos em seu centro urbano.

Dentro desses incentivos parisienses estão incluídos o financiamento de estudos de viabilidade e o fornecimento de áreas centrais para a instalação de ELU a preços acessíveis com o objetivo de reduzir os congestionamentos e a poluição, bem como a melhoria na eficiência da distribuição urbana. Em contrapartida, como exigências, há a consolidação de cargas em grandes veículos na periferia, para reduzir o tráfego de veículos de grande porte e a utilização de veículos ambientalmente amigáveis para o transporte da "última milha".

Dentro dessa perspectiva, citam-se duas experiências francesas que utilizaram o ELU como alternativa para atender a grande demanda de entrega de mercadorias: Chronopost e La Petite Reine. A primeira é uma subsidiária do grupo La poste, um dos maiores transportadores expressos da Europa. Atualmente, a empresa participa da entrega de produtos do comércio entre empresas e do comércio entre empresa e cliente. Com 3.500 empregados, a empresa realiza, em média, a entrega de 240.000 encomendas por dia em todo o mundo (TURBLOG, 2011).

Tendo em vista o aumento da demanda e a dispersão das instalações logísticas pela região metropolitana de Paris, a Chronopost mudou a sua logística de operação. Anteriormente, a empresa possuía um um CDU nas proximidades de Paris, em Charenton, de onde as mercadorias eram transportadas para diversos destinos na cidade. A partir de 2005, foi criado um ELU em um estacionamento na região central de Paris, que se tornou um ponto intermediário entre o CDU e os clientes, para atender os $7^{\circ}$ e $8^{\circ}$ distritos de Paris (TURBLOG, 2011).

A cada ano, 700.000 entregas são operacionalizadas em $950 \mathrm{~m}^{2}$. Os veículos utilizados para entrega têm capacidade variando de $1,5 \mathrm{~m}^{3}$ a 2,8 $\mathrm{m}^{3}$. (TURBLOG, 2011). Um estudo feito entre 2006 e 2008 mostrou os benefícios da iniciativa: A cada ano, deixou-se de percorrer $41.000 \mathrm{~km}$ e emitir 16,5 toneladas de gás carbônico, reduzindo em $75 \%$ os poluentes locais. Em 2013, um novo ELU começou operar no $15^{\circ}$ distrito de Paris. 
A empresa La Petite Reine foi criada em 2001 voltada para o transporte de mercadorias dentro dos centros de grande densidade populacional. Segundo TURBLOG (2011), a empresa realiza 2.500 entregas diárias utilizando dois ELUs (um próximo ao museu do Louvre e outro localizado no $6^{\circ}$ distrito) e veículos elétricos denominados cargocycles. Atualmente, é uma empresa do grupo Star Service, com distribuição com cargocycles em diferentes regiões de Paris.

Os cargocycles são triciclos elétricos com assistência para pedalar, com uma capacidade de 1,5 $\mathrm{m}^{3}$ e uma autonomia de 4 horas de circulação. Tem como vantagem a possibilidade de circulação em áreas de pedestres, evitando congestionamentos, operando com menor custo operacional e permissão de circulação em faixas para ônibus, além de ter caráter sustentável.

Estudo realizado entre 2003 e 2005, revelou que, em um ano, 600.000 toneladas de carga por quilômetro útil deixaram de serem transportadas por vans, 203 toneladas de gás carbônico não foram emitidas, houve uma redução considerável do ruído na cidade e 89 toneladas equivalentes de petróleo não foram emitidas por motores (TURBLOG, 2011).

Boudouin (2009) cita que um ELU pode processar 400 encomendas/dia em um espaço de $100 \mathrm{~m}^{2}$ e pode atender a comerciantes e domicílios localizados até 200 metros de raio da área. Contudo, as experiências indicam que esta área de abrangência pode ser maior. Para APUR (2016), um ELU pode ter uma área de até $3.000 \mathrm{~m}^{2}$. As áreas em que estacionamento é um fator problemático para a distribuição urbana são mais apropriadas para instalação de um ELU, pois esta solução tem foco em locais com difícil acesso. Importante ressaltar que a publicação de Boudouin (2009) foi resultado de uma ação federal para disseminar a implantação de ELUs na França. Mais recentemente, APUR (2016) lançou uma cartilha com diretrizes para implementação de Espaços Logísticos Urbanos, além de Plataformas Logísticas e Hotel Logístico. A cartilha detalha o modelo operacional e identifica áreas com potencial de implementação de ELU em Paris.

A experiência francesa inspirou sistemas semelhantes em diversas cidades utilizando a bicicleta de carga (ou cargobike) que, segundo Navarro et al. (2016), mostrou-se ser uma solução viável. Oliveira et al. (2014) simularam a operação de um ELU em Belo Horizonte, cujo principal resultado foi a economia de tempo nas operações urbanas. STRAIGHTSOL (2014) apresenta um teste piloto de entregas com bicicletas elétricas em Bruxelas (Bélgica). Browne et al. (2016) mencionam que a empresa Gnewt Cargo oferece serviços utilizando cargocycles em Londres (Inglaterra) e Gruber e Kinm (2016) descrevem o projeto utilizando bicicletas elétricas em cidades da Alemanha.

Taniguchi et al. (2016) relatam a utilização de bicicletas elétricas para entregas domiciliares a partir de uma estação de metrô (Estação Arashiyama) em Kyoto, com resultados que indicaram redução de $\mathrm{CO}_{2}$ e do número de veículos de carga utilizado para as entregas parceladas. Navarro et al. (2016) descrevem os resultados de um teste piloto no centro histórico de Barcelona e Valencia (Espanha) das entre- 
gas com triciclos elétricos, utilizando centros de consolidação urbano e terminais de transbordo (similares ao ELU). Os resultados foram analisados na perspectiva econômica, operacional, ambiental, social e da eficiência energética, e permitiram identificar fatores chaves para a implantação deste tipo de sistema, como a densidade comercial na área. Koç et al. (2016) analisam o impacto da localização de armazéns, composição da frota e roteamento na emissão de poluentes e entregas urbanas.

Pode-se perceber que a literatura foca na descrição de experiências exitosas, sem detalhamento metodológico da escolha da localização do ELU, apesar dos benefícios obtidos em todos os casos. Neste contexto, este trabalho reúne as experiências relatadas na literatura e contribui metodologicamente, com a combinação de modelos de localização e roteirização para definição da localização do ELU e do número de veículos necessários para atender a demanda, elementos importantes para analisar os benefícios econômicos e ambientais de um ELU.

\section{PROCEDIMENTO METODOLÓGICO}

Considerando o exposto na seção anterior, as experiências de ELU foram positivas, contudo não existe um procedimento metodológico para avaliar os benefícios da implantação.

Assim, a metodologia tem como base um estudo de aplicação com o objetivo de explorar situações da vida real cujos limites não estão claramente definidos (GIL, 2009). Para tanto, utiliza-se um procedimento metodológico (Figura 2) composto de três etapas: (i) definição da área de estudo, desenvolvimento da rede de transporte e definição das áreas candidatas para implantação de espaços logísticos urbanos, (ii) detalhamento dos cenários, utilizando modelos da pesquisa operacional e, (iii) análise resultados obtidos considerando aspectos logísticos (quilometragem percorrida, número de veículos, volume transportado, emissão de $\mathrm{CO}_{2}$ ) e econômicos (custo de aluguel, transporte e operação). O procedimento metodológico encontra-se detalhado a seguir. 
Figura 2 - Procedimento metodológico para a avaliação da implantação do ELU

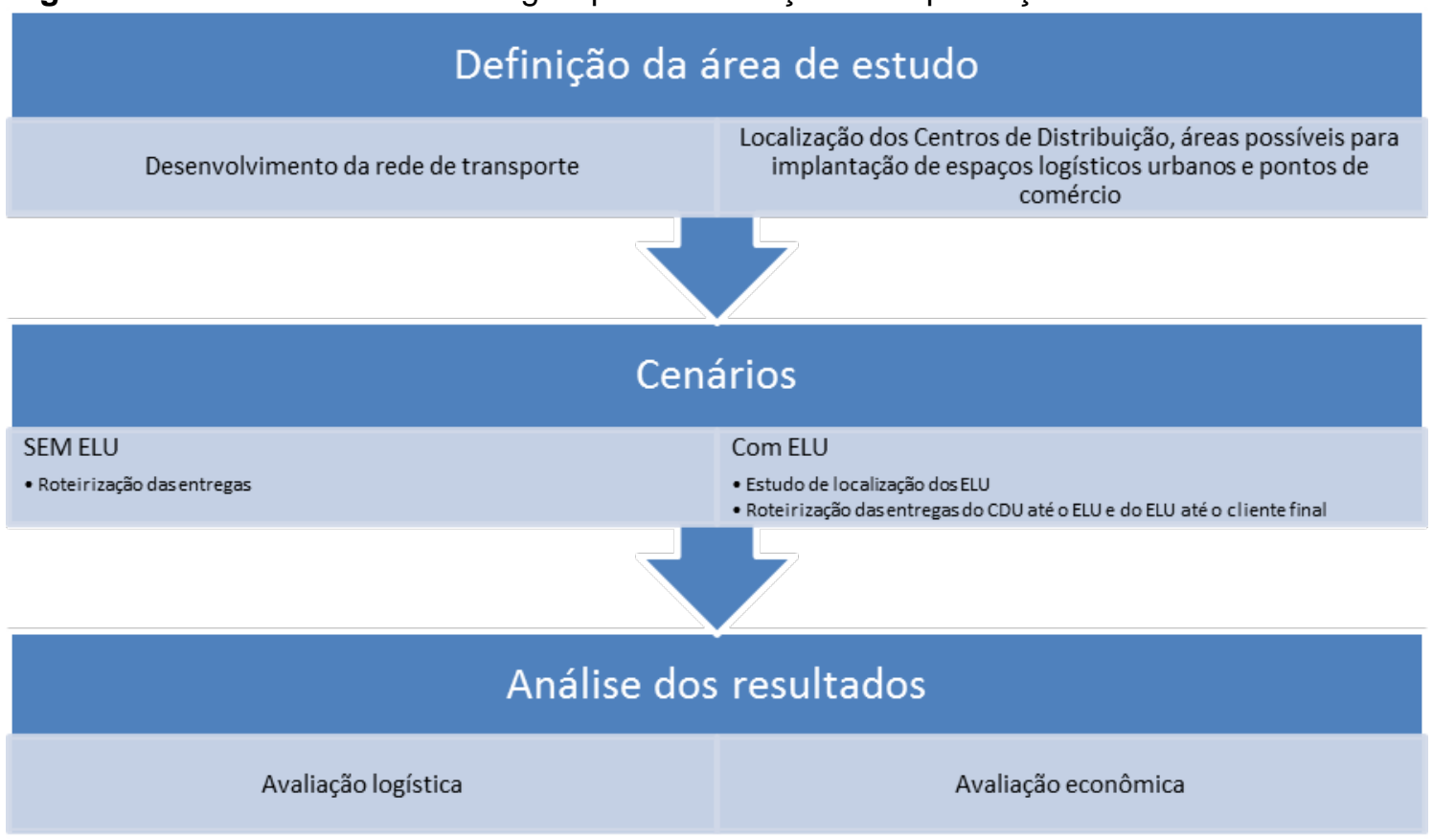

\subsection{Definição e caracterização da área de estudo}

Primeira cidade planejada do Brasil, Belo Horizonte foi projetada pelo engenheiro Aarão Reis e inaugurada no dia 12 de dezembro de 1897 por Chrispim Jaques Bias Fortes, governador do Estado de Minas Gerais. Inicialmente, a cidade foi planejada para abrigar cerca de 400 mil habitantes, mas ao longo do século XX, sobretudo nas décadas de 1940 a 1960, a população cresceu muito, ultrapassando esse limite. $O$ desenvolvimento econômico da cidade trouxe novos problemas, sendo o aumento da frota de veículos o principal deles. Atualmente, a capital tem $331,401 \mathrm{~km}^{2}$, uma população de 2.375.151 habitantes, com uma frota composta por 1.620.801 veículos e Índice de Desenvolvimento Humano (IDH) de 0,81. A cidade é constituída de nove regiões administrativas e sua região metropolitana $(\mathrm{RMBH})$ é composta por 34 municípios.

O Produto Interno Bruto de Belo Horizonte é de aproximadamente 55 bilhões de reais, sendo que o setor de comércio e serviços contribui com $58,7 \%$ desse valor. A grande maioria dessas atividades se concentra no hipercentro da capital, que possui densidade demográfica de 8.612,1 habitantes $/ \mathrm{km}^{2}$ (PBH, 2011). Considerando esse contexto, escolheu-se o Hipercentro de Belo Horizonte como região de estudo por ser uma área com alta concentração de comércio. A análise foi realizada para o setor de vestuário, com expressiva movimentação de mercadorias na região central de Belo Horizonte (OLIVEIRA, 2014).

Foram considerados 339 lojas do setor de vestuários e 35 pontos candidatos a ELU. Para definição dos pontos candidatos, foram consideradas as áreas de estacionamento que poderiam ser convertidas em Espaços Logísticos Urbanos. Esta 
premissa considerou o fato de que na Europa, os ELUs, em geral, são implementados em estacionamentos ou áreas públicas.

Além disso, considerou-se como premissa neste estudo, que os CDUs propostos por Oliveira e Correia (2014) atenderiam a região como centros de distribuição, por falta desta informação real. Para tanto, considerou-se que toda a mercadoria é proveniente de um CDU localizado na BR-381, em Santa Luzia.

\subsubsection{Elaboração da rede de transporte}

Para as análises, o arruamento da região de estudo foi desenvolvido no TransCAD ${ }^{\circledR}$. Para isso, importou-se um arquivo em formato shape (extensão ".shp") contendo todas as ruas da cidade de Belo Horizonte e as respectivas características. Essas ruas foram utilizadas como base para a reconstrução manual de todas as vias do centro de Belo Horizonte (toda a região compreendida dentro da Avenida do Contorno), pois o TransCAD ${ }^{\circledR}$ não permite a edição de dados de arquivos em formato ".shp" (somente faz leitura desses arquivos).

Com a rede de transporte finalizada, importaram-se os pontos referentes à localização das 339 lojas e 35 pontos candidatos para instalação do ELU. Estas informações foram obtidas do Cadastro Municipal de Contribuintes, da Prefeitura de Belo Horizonte, que contém o endereço, a atuação, a atividade comercial e a área do imóvel dos contribuintes do município. Por fim, conectou-se cada um desses pontos à rede de transportes utilizando a ferramenta connect do TransCAD ${ }^{\circ}$.

Neste estudo foi considerado que o volume total diário para entrega utilizado no estudo foi de $8.700 \mathrm{~kg} /$ dia e foi utilizada a base de dados de uma empresa transportadora de mercadorias, com entregas no setor de vestuário.

\subsection{Cenários}

Para análise da eficiência de um ELU como intermediário na entrega de mercadorias no hipercentro de Belo Horizonte, foram definidos dois cenários. O cenário 1 representa a situação atual de entrega de mercadorias em Belo Horizonte, em que os veículos que realizam as entregas têm menos de 6,5 metros de comprimento e capacidade de 5 toneladas. Eles saem de um CDU localizado na região metropolitana de Belo Horizonte e transportam toda a mercadoria diretamente para as lojas (pontos de estudo). Considerou-se que em cada parada, o veículo dispende, em média, 10,2 minutos para estacionar e realizar a entrega (OLIVEIRA, 2014; OLIVEIRA; DIAS, 2014).

O cenário 2 representa a situação hipotética de utilização de um ELU como intermediador na entrega de mercadorias no hipercentro de Belo Horizonte. O ELU é escolhido entre os 35 pontos candidatos, por meio de um modelo de localização de facilidades. Como o volume considerado neste estudo é baixo, optou-se por escolher apenas um ELU. Contudo, pode-se considerar a localização de mais de um ELU pa- 
ra maiores volumes. Um veículo de carga de 20 toneladas é utilizado para transportar a mercadoria para atender a demanda das lojas, do CDU para o ELU. A partir daí, dois cenários são considerados: No primeiro (cenário 2.a), a mercadoria é entregue por caminhões de 5 toneladas e comprimento menor que 6,5 metros considerando um tempo de parada de 10,2 minutos e tendo como origem o ELU. No cenário 2.b. são utilizados triciclos elétricos com capacidade $180 \mathrm{~kg}$ de carga para a entrega de mercadorias.

\subsubsection{Determinação do melhor local para a implantação do ELU}

A localização dos ELUs foi determinada pelo TransCAD®, através da ferramenta facility location (localização de facilidades). O modelo de localização de facilidades utilizado no software se atenta em realizar a alocação dos ELUs, considerando locais candidatos disponibilizados pelo usuário. Assim, após realizar o trade-off entre os custos e benefícios da implementação da instalação em cada possível local, as facilidades são definidas.

Após obter a localização do ELU, utilizou-se a ferramenta vehicle routing (roteamento de veículos) para a definição das rotas de entrega. Nesta ferramenta, cada veículo tem uma rota que se inicia no ELU, passar por um ou mais clientes, denominados como paradas, e finaliza a rota retornando ao mesmo local inicial. O objetivo deste modelo é obter um conjunto de rotas que minimiza o tempo total ou distância percorrida pela frota de veículos, atendendo a todos os clientes.

\subsection{Análise dos resultados}

Para proceder à análise dos resultados, algumas premissas foram consideradas sobre veículos utilizados, detalhadas a seguir.

\subsubsection{Informações dos veículos utilizados}

Foram considerados dois tipos de veículo: O primeiro (veículo 1) atende a legislação vigente em Belo Horizonte, com comprimento inferior a 6,5 metros e capacidade máxima de 5 toneladas. Ele percorre aproximadamente 5,5 quilômetros por litro de diesel e possui custo fixo mensal de $R \$ 7.687,28$, valor que inclui aquisição, manutenção e salário do motorista (NTC, 2013). Considerou-se, como premissa, que a velocidade média no centro de Belo Horizonte é de $16 \mathrm{~km} / \mathrm{h}$. Esse veículo é utilizado no cenário 1 e no cenário 2.a na distribuição de mercadorias do ELU para as lojas.

O veículo 2 possui aproximadamente 9 metros de comprimento e capacidade de 20 toneladas. Seu rendimento médio é de 3,64 quilômetros por litro de diesel e seu custo fixo mensal é de R\$9.599,45 (NTC, 2013), valor que também inclui aquisição, manutenção e salário do motorista. Esse caminhão é utilizado no cenário 2.a 
e no cenário 2.b para transportar as mercadorias do CDU para o ELU, antes das 7:00 da manhã, pois sua circulação é proibida depois desse horário na área central de Belo Horizonte.

Além disso, o cenário 2.b utiliza triciclo elétrico. Para tanto, considerou-se triciclos com capacidade de $180 \mathrm{~kg}$ e autonomia de $6 \mathrm{~km} / \mathrm{kwh}$. O custo anual é de $\mathrm{R} \$$ 250,00, fornecido por loja especializada em Belo Horizonte, que inclui manutenções e trocas de pneus, freios e câmaras de ar. O custo por quilômetro percorrido é de R\$ 0,0835 . A velocidade de um triciclo elétrico no centro da cidade foi estimada em 12 $\mathrm{km} / \mathrm{h}$.

\subsubsection{Custo do ELU}

O custo de instalação e manutenção do ELU é baseado em duas parcelas: o custo de aluguel e IPTU do imóvel e, o custo de operação. Para a primeira parcela foi considerado o preço médio de aluguel por metro quadrado de um galpão na região Centro-Sul de Belo Horizonte em agosto de 2013, i.e. $\mathrm{R} \$ 24,83 / \mathrm{m}^{2}$ (IPEAD, 2013). Considerando uma área de $600 \mathrm{~m}^{2}$, de maneira similar à área adotada pelo ELU da empresa La Petit Reine, o aluguel mensal equivaleria a R $\$ 14.898,00 /$ mês.

Para definir o custo de operação, considerou-se necessário duas pessoas destinadas às atividades dentro do ELU (separação e montagem dos pedidos). $O$ número de funcionários destinados às entregas com o triciclo foi estimado segundo a capacidade de cada instalação. Para calcular os valores, definiu-se como premissa que um funcionário consegue realizar, em média, quatro entregas com carregamento total do triciclo por hora, cerca de 35 por dia, sendo essa quantidade correspondente a menos da metade das entregas do Chronopost, já que segundo TURBLOG (2011), por dia, a empresa realiza 72 entregas/funcionário). Assim, esse valor se torna aceitável pelo fato do hipercentro de Belo Horizonte possuir mais aclives quando comparado ao $7^{\circ}$ e $8^{\circ}$ bairros de Paris. O salário base destes trabalhadores é de um salário mínimo por mês, i.e. $\mathrm{R} \$ 678,00$ com o benefício de transporte no valor de $\mathrm{R} \$ 117,00$. Considerando os encargos sociais e benefícios exigidos por lei, o total gasto com cada funcionário por mês passa a ser $\mathrm{R} \$ 1.112,91$.

\subsubsection{Impactos ambientais}

O setor de transportes é um dos principais emissores de gases estufas, sobretudo $\mathrm{CO}_{2}$ (DABLANC, 2007). Devido a esse fato, torna-se importante quantificar as taxas de $\mathrm{CO}_{2}$ emitidas pelos veículos utilizados no transporte de mercadorias nos cenários deste estudo, visto que uma das vantagens das soluções de logística urbana é a redução das emissões. Para tanto, utilizou-se o estudo de emissão de poluentes (Carvalho, 2011), em que são definidas as taxas de emissão de $\mathrm{CO}_{2}$ conforme o tipo de veículo. O veículo elétrico emite $0,087 \mathrm{~kg} \mathrm{CO} / \mathrm{kWh}$ e os veículos de carga no ciclo diesel emitem $3,2 \mathrm{~kg} \mathrm{CO} / \mathrm{l}$. 
A emissão para o veículo elétrico foi calculada baseada na matriz elétrica brasileira no ano de 2008 , em que a hidroeletricidade representava $84 \%$ do fornecimento de energia para o País. Já o cálculo da emissão dos veículos pesados movidos a diesel foi baseado em Álvares e Linke (2001) e Soares et al. (2009), considerando-se a soma de duas parcelas: o valor de $2,6 \mathrm{~kg}$ de $\mathrm{CO}_{2}$ para cada litro de diesel queimado na combustão e o valor médio de $0,5 \mathrm{~kg}$ de $\mathrm{CO}_{2}$ emitidos para produzir e distribuir o combustível. Analisando a emissão por tipo de veículo e seu respectivo rendimento, chega-se à emissão de $\mathrm{CO}_{2}$ por quilômetro percorrido, em que:

- Veículo 1 emite $0,582 \mathrm{~kg} \mathrm{CO} / \mathrm{km}$;

- Veículo 2 emite $0,879 \mathrm{~kg} \mathrm{CO} / \mathrm{km}$;

- Triciclo elétrico emite $0,015 \mathrm{~kg} \mathrm{CO} / \mathrm{km}$.

\section{RESULTADOS}

O resultado da roteirização para o cenário 1 indicou ser necessário seis caminhões do tipo 1 para entregar a mercadoria em 339 estabelecimentos comerciais. Os veículos percorreriam diariamente $235,9 \mathrm{~km}$ e transportariam, em média, 1.454,9 $\mathrm{kg}$. O cenário 1 fornece um fator de ocupação do veículo de apenas 29\%. Para cumprir com as rotas seria emitido $137,3 \mathrm{~kg}$ de $\mathrm{CO}_{2}$. A Tabela 1 apresenta os resultados consolidados para os cenários 1 e $2 \mathrm{a}$.

Para o cenário $2 \mathrm{a}$, o resultado indicou a utilização de um veículo de 20 toneladas (veículo 2) para transportar toda a mercadoria (8,7 toneladas) do CDU para o ELU e cinco veículos do tipo 1 para transportar as mercadorias até as lojas. A distância total percorrida foi de $71,42 \mathrm{~km}$, considerando o percurso do CDU até o ELU de $29,51 \mathrm{~km}$. Neste cenário, o fator de carga entre o ELU até os pontos de entrega é de $34,9 \%$ e a emissão total de $\mathrm{CO}_{2}$ é de $50,76 \mathrm{~kg}$.

Tabela 1 - Resultados obtidos em relação a distância e volume transportado

\begin{tabular}{cccrcrr}
\hline & \multicolumn{2}{c}{ CENÁRIO 1 } & \multicolumn{2}{c}{ CENÁRIO 2a } & \multicolumn{2}{c}{ CENÁRIO 2b } \\
\hline Rota & $\begin{array}{c}\text { Distância } \\
(\mathrm{km})\end{array}$ & $\begin{array}{c}\text { Volume } \\
(\mathrm{kg})\end{array}$ & $\begin{array}{c}\text { Distância } \\
(\mathrm{km})\end{array}$ & $\begin{array}{c}\text { Volume } \\
(\mathrm{kg})\end{array}$ & $\begin{array}{c}\text { Distância } \\
(\mathrm{km})\end{array}$ & $\begin{array}{c}\text { Volume } \\
(\mathrm{kg})\end{array}$ \\
1 & 39,2 & $1.067,2$ & 11,1 & 906,8 & 29,51 & 8.700 \\
2 & 38,3 & 917,6 & 7,3 & $1.924,5$ & - & - \\
3 & 40,8 & $1.744,6$ & 8,3 & $1.739,6$ & - & - \\
4 & 41,5 & $1.848,5$ & 6,9 & 882,6 & - & - \\
5 & 42,4 & 920,3 & 8,3 & $3.275,8$ & - & - \\
6 & 33,8 & $2.231,1$ & - & - & - & - \\
Total & 2359 & $8.729,3$ & 41,9 & $8.729,2$ & 29,51 & $8.729,2$ \\
\hline
\end{tabular}

No cenário 2.b, os resultados indicaram a utilização do veículo 2 para transportar toda as mercadorias do CDU para o ELU e quatro triciclos elétricos para transportar as mercadorias até as lojas. A distância total percorrida (obtida através 
da soma da distância percorrida pelos triciclos com a distância percorrida pelo veículo 2, no caso $29,51 \mathrm{~km}$ ) foi de $116,21 \mathrm{~km}$ e a carga média transportada foi de 167,72 $\mathrm{kg}$. Os quatro triciclos seriam responsáveis por 39 rotas durante a janela de tempo de 7:00h-19:30h. Como a capacidade do triciclo é pequena, eles operam com um fator de carga de 93\%. Sua utilização implica em uma emissão de $28,26 \mathrm{~kg}$ de $\mathrm{CO}_{2}$.

A Tabela 2 apresenta o resumo dos resultados dos cenários analisados. Com relação à distância, nota-se que, sem a presença do ELU, os veículos realizam um trajeto maior, contribuindo para o aumento do volume de tráfego nas vias urbanas. Já os triciclos percorrem uma distância maior que os veículos do cenário $2 a$, que pode ser explicado devido à baixa capacidade de transporte de carga de cada um deles $(180 \mathrm{~kg})$. Assim, muitas viagens podem levar mercadoria exclusivamente para uma loja, obrigando o triciclo a fazer mais viagens/dia e, consequentemente, percorrer uma distância maior.

Analisando o fator de carga, é possível identificar que os veículos do cenário 1 e 2 a têm a sua capacidade de transporte subaproveitada, com um fator de carga inferior a 35\%. Apesar disso, pelos resultados encontrados, pode-se afirmar que com o ELU, a capacidade do veículo é mais bem utilizada, implicando em aumento da eficiência do transporte. Os triciclos elétricos, por sua vez, utilizam quase toda a capacidade de carga, visto que só podem transportar um máximo de $180 \mathrm{~kg}$. Além disso, os triciclos elétricos têm maior mobilidade no tráfego urbano, favorecendo as inúmeras viagens que devem ser realizadas em virtude da baixa capacidade de carga.

Tabela 2 - Resumo dos resultados em relação ao fator de carga e emissão de $\mathrm{CO}_{2}$

\begin{tabular}{crrr}
\hline Cenário & Distância $(\mathrm{km})$ & Fator de carga $(\%)$ & Emissão de $\mathrm{CO}_{2}(\mathrm{~kg})$ \\
\hline Cenário 1 & 235,9 & 29,0 & 137,3 \\
Cenário 2a & 71,4 & 34,9 & 50,8 \\
Cenário 2b & 116,2 & 93,2 & 28,3 \\
\hline
\end{tabular}

Em relação às emissões diárias de $\mathrm{CO}_{2}$, observa-se que o cenário considerando a utilização de triciclos elétricos é o menos poluente e o cenário $2 \mathrm{a}$, que também utiliza o ELU, é menos poluente que o cenário 1. Portanto, a utilização do ELU como intermediário na entrega de mercadorias, apesar de quase não reduzir o número de veículos utilizados (cenário 2a), diminui consideravelmente a distância total percorrida. Com uma menor distância percorrida pelos veículos de carga, a emissão de $\mathrm{CO}_{2}$ também diminui.

A Tabela 3 apresenta o custo total de operação para os cenários analisados. Os custos, em relação a transporte e funcionários, para os cenários 1 e 2a são semelhantes, e a utilização do ELU implica em um acréscimo mensal de 20\% devido ao aluguel. Assim, a implantação de ELU e a utilização de caminhões na entrega da "última milha" só se torna economicamente viável com subsídios financeiros para 
redução dos custos com locação. Tal subsídio foi implantado inicialmente em Paris para dar viabilidade financeira (TURBLOG, 2011).

Tabela 3 - Custo total dos cenários analisados

\begin{tabular}{lrcrrr}
\hline Cenário & $\begin{array}{c}\text { Custo de trans- } \\
\text { porte }(\mathrm{R} \$ / \mathrm{mês})\end{array}$ & $\begin{array}{c}\text { Custo do funci- } \\
\text { onário } \\
(\mathrm{R} \$ / \mathrm{mês})\end{array}$ & $\begin{array}{c}\text { Custo locação } \\
\text { do ELU } \\
(\mathrm{R} \$ / \mathrm{mês})\end{array}$ & $\begin{array}{r}\text { Custo total } \\
(\mathrm{R} \$ / \mathrm{mês})\left(^{*}\right)\end{array}$ \\
\hline Cenário 1 & $49.210,90$ & $6.677,46$ & 0 & $55.888,36$ \\
Cenário 2a & $48.597,28$ & $6.677,46$ & $14.898,00$ & $70.743,27$ \\
Cenário 2b & $10.312,26$ & $5.564,55$ & $14.898,00$ & $33.000,00$ \\
\hline
\end{tabular}

${ }^{*}$ ) considerando um dia de operação e o pagamento de funcionário e aluguel mensal

Contudo, quando os custos dos cenários 1 e 2b são comparados, observa-se uma economia de 40\%. Este resultado implica que, além da utilização de triciclos elétricos ser uma solução sustentável para a mobilidade da carga (prevista na Lei $n^{\circ}$ 12.587 de 3 de janeiro de 2012, que institui a Política Nacional da Mobilidade Urbana), é uma solução financeiramente viável. Tal resultado corrobora com as mais de cinquenta empresas de entrega expressa que surgiram no Brasil nos últimos anos, usando a bicicleta como modo de transporte e os exemplos de entrega por bicicleta na cidade do Rio de Janeiro (BINATTI; LOBO, 2014).

\subsection{Discussão dos resultados}

Os resultados obtidos nesta aplicação demonstram que o Espaço Logístico Urbano é uma solução economicamente e ambientalmente viável para o transporte urbano de mercadorias. A implementação de ELUs em áreas urbanas tem potencial para reduzir o número de veículos e, se utilizado modos não-motorizados para as entregas, a emissão de poluentes, melhorar o ambiente urbano, além de contribuir para a sustentabilidade do transporte de carga.

Ainda, os resultados aqui obtidos convergem para os preconizados pela Lei $n^{\circ}$ 12.587 de 3 de janeiro de 2012, que institui a Política Nacional da Mobilidade Urbana. Contudo, a literatura ainda é escassa na demonstração de que soluções são aplicáveis na realidade brasileira.

O procedimento metodológico apresentado neste estudo é simples sem ser simplista e permite obter resultados para alguns indicadores do transporte urbano de mercadorias. A utilização de modelos clássicos de pesquisa operacional, utilizados através do TransCAD ${ }^{\circledR}$, demonstram que diferentes ferramentas podem ser utilizadas para obtenção dos resultados. Neste estudo, utilizou-se um software comercial, contudo qualquer plataforma que permita obter resultados de modelos de localização e roteirização pode ser utilizada.

Por fim, é importante destacar que o transporte urbano de mercadorias é um elemento vital para o desenvolvimento das cidades. Soluções que minimizem os 
problemas, propondo rentabilidade e sustentabilidade à atividade são importantes e precisam ser consideradas para a disseminação das práticas no contexto brasileiro. Como forma de estímulo, políticas públicas que forneçam subsídio nos anos iniciais da operação podem incentivar a implementação desta solução. O subsídio por consistir no fornecimento de infraestrutura, isenção de IPTU e/ou outros impostos.

\section{CONSIDERAÇÕES FINAIS}

Os resultados obtidos neste estudo demonstram que a utilização do Espaço Logístico Urbano como intermediador na entrega de mercadorias no centro de Belo Horizonte é vantajosa, apesar dos custos de operação. Com este trabalho, observou-se também que o ELU consolida o transporte de mercadorias na medida em que possibilita um melhor aproveitamento do espaço disponível nos veículos de cargas.

Contudo, a consolidação só é realidade se a demanda for compatível com a capacidade dos veículos. Assim, é necessário avaliar o tipo de veículo a ser utilizado para as entregas urbanas. No caso analisado, considerando o setor de vestuário, a utilização de triciclos elétricos mostrou-se adequada principalmente pela baixa emissão de $\mathrm{CO}_{2}$, baixo custo de operação e a alta produtividade dos triciclos. Caso houvesse uma demanda maior, mais triciclos poderiam ser alocados, mantendo, mesmo assim, um cenário de transporte sustentável.

Além disso, a utilização de triciclos elétricos melhora de maneira significativa o ambiente urbano. Além de serem mais ágeis no tráfego urbano, os triciclos não dispendem tempo procurando vagas para estacionar e emitem uma pequena quantidade de gases de efeito estufas no meio ambiente, quando comparado com veículos diesel. Assim, os triciclos contribuem para melhorar a qualidade de vida da população, constantemente afetada pela poluição do ar, pela poluição sonora e pelos congestionamentos. Contudo, um fator crucial para este tipo de sistema de entrega é o modelo econômico a ser adotado.

Para futuros trabalhos, sugere-se a investigação dos custos reais da operação de um Espaço Logístico Urbano no contexto brasileiro, visto que este estudo baseou-se em informações internacionais. O estudo do modelo econômico também é importante visto que este é um elemento crucial para a implantação do ELU, podendo ser analisados os benefícios de diferentes modelos. Ainda, a investigação dos impactos da distribuição utilizando veículos movidos a Gás Natural pode trazer interessante contribuição técnica à discussão no contexto brasileiro. Além disso, a solução aqui analisada pode ser avaliada sob o ponto de vista do urban manufacturing e industry 4.0 .

Por fim, soluções como a explorada neste trabalho são importantes considerando a necessidade de investir em soluções sustentáveis de mobilidade urbana para pessoas e mercadorias. Sendo a entrega urbana muitas vezes percebida como a vilã da mobilidade, investir em soluções alternativas que garantam que a entrega 
seja realizada em sua integralidade é importante tanto para uma mudança de paradigma quanto para a melhoria da qualidade de vida dos centros urbanos.

\section{AGRADECIMENTOS}

Os autores agradecem ao Conselho Nacional de Desenvolvimento Científico e Tecnológico (CNPq) pelo suporte à pesquisa e pela bolsa de Iniciação Científica.

\section{REFERÊNCIAS}

ÁLVARES JÚNIOR, O. M.; LINKE, R. R. A. Metodologia simplificada para cálculo das emissões de gases de efeito estufa de frotas de veículos no Brasil. São Paulo: CETESB, 1999.

APUR. Insérer des espaces logistiques dans le tissu dense: principes d'aménagements et exemples de transformation de délaissés. Paris: Atelier Parisien d'Urbanisme, 2016.

BINATTI, G.; LOBO, Z. O Uso de Bicicletas e Triciclos para Transporte Urbano de Carga e Logística na Cidade do Rio de Janeiro. In: XVIII CLATPU, 2014, Rosario. Proceedings...Rosario: Fundación Latinoamericana de Transporte Público y Urbano, 2014. 1-9.

BOUDOUIN, D. Les espaces logistiques urbains: guide méthodologique. Paris: La Documentation française, 2009.

BOUDOUIN, D.; MOREL, M., GARDART, M. Supply Chains and Urban Logistics Platforms. In: Gonzalez-Feliu, J.; Semet, F.; Routhier, J. L. (eds) Sustainable Urban Logistics: Concepts, Methods and Information Systems. Berlin: Springer, 2014. p. 1-20. http://dx.doi.org/10.1007/978-3-642-31788-0

BROWNE, M.; ALLEN, J.; ALEXANDER, P. Business improvement districts in urban freight sustainability initiatives: a case study approach. Transportation Research Procedia, v.12, p. 450-460, 2016. http://dx.doi.org/10.1016/j.trpro.2016.02.079

CARVALHO, C. H. R. Emissões relativas de poluentes do transporte motorizado de passageiros nos grandes centros urbanos brasileiros. Brasília: Instituto de Pesquisa Econômica Aplicada. 2011.

CRAINIC, T. G.; RICCIARDI, N.; STORCHI, G. Advanced freight transportation systems for congested urban areas. Transportation Research Part C, v.12, p. 119-137, 2004. http://dx.doi.org/10.1016/j.trc.2004.07.002

DABLANC, L. Goods transport in large European cities: Difficult to organize, difficult to modernize. Transportation Research Part A: Policy and Practice, v.41, n.3, p. 280-285, 2007. http://dx.doi.org/10.1016/j.tra.2006.05.005

DABLANC, L. City distribution, a key elements of the urban economy: guidelines for practioners. In: MACHARIS, C.; MELO, S. City distribution and urban freight transport: multiple perspectives. Cheltenham, Northampton: Edward Elgar, 2014.

DABLANC, L.; GIULIANO, G.; HOLLIDAY, K.; O'BRIEN, T. Best Practices in Urban Freight 
Management : Lessons from an International Survey. In: TRB, 2013, Boston. Proceedings... Boston: Transportation Research Record (TRR), 2013. 1-22.

FRELON Premières solutions immobilières pour le développement d'une logistique respectueuse du milieu urbain. Paris: Mines Paris-Tech \& Sogaris, 2011.

Gil, A. C. Como elaborar projetos de pesquisa. São Paulo: Editora Atlas, 2009.

GRUBER, J.; KIHM, A. Reject or Embrace? Messengers and Eletric Cargo Bikes. Transportation Research Procedia, v.12, p. 900-910, 2016. DOI

http://dx.doi.org/10.1016/j.trpro.2016.02.042

HEITZ, A. Paris, Urban Laboratory for Urban Logistics. Marne-la-Valée: MetroFreight Center of Excellence, 2015. 26p. (Project Number: 15-2.1.c. Feasibility of consolidated freight deliveries in cities and alternatives for more efficient use of road and parking spaces in cities).

IPEAD. Pesquisa do mercado imobiliário em Belo Horizonte: aluguéis - Agosto de 2013. Belo Horizonte: Fundação Instituto de Pesquisas Econômicas Administrativas e Contábeis de Minas Gerais, 2013

KOÇ, Ç.; BEKTAS, T.; JABALI, O.; LAPORTE, G. The impact of depot location, fleet composition and routing on emissions in city logistics. Transportation Research Part B, v. 84, p. 81-102, 2016. http://dx.doi.org/10.1016/j.trb.2015.12.010

NAVARRO, C.; ROCA-RIU, M.; FURIÓ, S.; ESTRADA, M. Designing new models for energy efficiency in urban freight transport for smart cities and its application to the Spanish case. Transportation Research Procedia, v.12, p. 314-324, 2016. http://dx.doi.org/10.1016/j.trpro.2016.02.068

NTC. Planilha de custos do percurso rodoviário de carga lotação. São Paulo: Associação Nacional do Transporte de Cargas e Logística, 2013.

OECD. Delivering the goods, 21st century challenges to urban goods transport. Paris: OECD, 2003.

OLIVEIRA, G. F.; OLIVEIRA, L. K. Stakeholders' perceptions of city logistics: an exploratory study in Brazil. Transportation Research Procedia, v.12, p. 339-347, 2016.

http://dx.doi.org/10.1016/j.trpro.2016.02.070

OLIVEIRA, L. K. Diagnóstico das vagas de carga e descarga para a distribuição urbana de mercadorias: um estudo de caso em Belo Horizonte. Journal of Transport Literature, v. 8, n.1, p. 178-209, 2014. http://dx.doi.org/10.1590/S2238-10312014000100009

OLIVEIRA, L. K.; CORREIA, V. A. Proposta metodológica para avaliação dos benefícios de um centro de distribuição urbano para mitigação dos problemas de logística urbana. Journal of Transport Literature, v. 8, n. 4, p.109-145, 2014. http://dx.doi.org/10.1590/22381031.jtl.v8n4a5

OLIVEIRA, L. K.; OLIVEIRA, B. R. P.; CORREIA, V. A. Simulation of an urban logistic space for the distribution of goods in Belo Horizonte, Brazil. Procedia - Social and Behavioral 
Sciences, v.125, p. 496-505, 2014. http://dx.doi.org/10.1016/j.sbspro.2014.01.1491

OLIVEIRA, L. K.; DIAS, E. G. A diagnosis methodology for urban goods distribution: a case study in Belo Horizonte City (Brazil). Procedia - Social and Behavioral Sciences, v. 125, p.199-211, 2014. http://dx.doi.org/10.1016/j.sbspro.2014.01.1467

PBH. Mapas e dados estatísticos. Belo Horizonte: Prefeitura de Belo Horizonte 2011.

PRATA, B. A.; OLIVEIRA, L. K.; DUTRA, N. G. S.; PEREIRA NETO, W. A. Logística urbana: fundamentos e aplicações. Curitiba: Editora CRV, 2012.

SOARES, L., ALVES, B. J. R., URQUIAGA, S., BODDEY. R. M. Mitigação da emissão de gases efeito estufa pelo uso de etanol da cana de açúcar produzido no Brasil. Seropédica:. Embrapa, 2009 (Circular Técnica $n^{\circ}$. 27)

STRAIGHTSOL. Strategies and measures for smarter urban freight solutions. Oslo: European Community Framework Programme 7, 2015. 32p. (Grant n. 285295)

SUGAR. City Logistics Best Practices: a handbook for authorities. Bologna: Sugar Logistics, 2011.

TANIGUCHI E., R. G. THOMPSON, T. YAMADA, R, V. DUIN. City Logistics: network. modelling and intelligent transport systems. Bingley: Elsevier Science Limited, 2001.

TANIGUCHI, E.; THOMPSON, R. G.; YAMADA, T. New opportunities and challenges for city logistics. Transportation Research Procedia, v.12, p. 450-460, 2016. DOI

http://dx.doi.org/10.1016/j.trpro.2016.02.004

TANIGUCHI, E.; THOMPSON, R.G.; YAMADA, T. Visions for City Logistics. In: TANIGUCHI, E.; THOMPSON, R. G. Logistics systems for sustainable cities. New York: Elsevier, New York, 2004.

TURBLOG. Deliverable 3.1:urban logistics practices: Paris case study. Transferability of urban logistics concepts and practices from a world wide perspective, 2011 (Grant Agreement no.SCS8-GA-2009-234061)

VAN DUIN, J. H. R.; GOFFAU, W.; WIEGMANS, B.; TAVASSZY, L. A.; SAES, M. Improving home delivery efficiency by using principles of address intelligence for $\mathrm{B} 2 \mathrm{C}$ deliveries.

Transportation Research Procedia, v. 12, p. 14-25, 2016. DOI

http://dx.doi.org/10.1016/j.trpro.2016.02.006

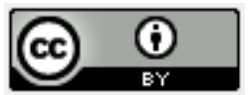

Artigo recebido em 04/01/2016 e aceito para publicação em 04/08/2016

DOI: http://dx.doi.org/ 10.14488/1676-1901.v16i3.2307 